\title{
An Analysis of Cultural Differences in Chinese and English First-person Deixis from the Perspective of Pragmatic Empathy
}

\author{
Shirong Zhang (corresponding author) \\ School of Foreign Languages, Lan Zhou University of Technology, China \\ Xiuxiu $\mathrm{Wu}$ \\ School of Foreign Languages, Shan Xi Normal University, China \\ Yue Feng \\ School of Foreign Languages, Lan Zhou University of Technology, China
}

\begin{abstract}
The first-person deixis, as an essential component of pragmatics, may indicate the social status, interpersonal relationship and other factors of the conversational parties, thus reflecting the implicit cultural in a particular society. Therefore, the different uses in first-person deixis of different languages may imply the cultural differences among different societies. In view of this, based on the theory of pragmatic empathy, this thesis attempts to explore the implied cultural differences reflected in the specific uses of the first-person deixis in English and Chinese.
\end{abstract}

Index Terms - first-person deixis, pragmatic empathy and de-empathy, cultural differences

\section{INTRODUCTION}

Deixis remains a major topic of discussion in the pragmatic field, meaning "pointing" or "indicating". Levinson (1983) gives five categories of deixis: person deixis, place deixis, time deixis, discourse deixis and social deixis. As Ran Yongping (2007)puts it, the function of person deixis consists in the embodiment of emotional or psychological divergence or convergence of the addresser and the addressee, thereby creating social distance or proximity between the two sides, which just corresponds to the two concepts: pragmatic empathy and pragmatic de-empathy.

The term empathy means "the process of putting yourself into someone else's shoes, of reaching beyond the self and understanding and feeling what another person is understanding or feeling." (Brown, 1987, p.107). In the application of empathy to pragmatics, He Ziran (1991) proposed the concept of pragmatic empathy, which refers to the experience of achieving emotional convergence, or of reaching the emotional resonance between the addresser and the addressee by bringing the social, cultural backgrounds of both parties and the communicative context into consideration. Naturally, the opposite side of pragmatic empathy constitutes the concept of pragmatic de-empathy initially proposed by Ran (2007)in counterpoint to pragmatic empathy, referring to the experience of achieving emotional distance between the addresser and the addressee on the basis of considering the social, cultural backgrounds of communicators and the communicative context .

The Chinese and English person deixis, deeply rooted in different cultural backgrounds, may be endowed with some different cultural connotations in their empathetic aspect. This paper, therefore, attempts to offer both English and Chinese learners a brief glimpse of the implicit cultural disparities embodied in different usage of Chinese and English first-person deixis from the perspective of pragmatic empathy.

\section{Contrastive Study on I in English And Zan, wo in Chinese And Other Self-Depreciatory Chinese Deixis}

\section{A. zan, wo in Chinese and Other Self-depreciatory Chinese Deixis}

By speaking zan which actually means the addresser himself on one hand, but also puts himself in an empathetic stance as one member of a whole community on the other, the addresser shortens the psychological distance with the addressee, for example,

(1) 要说当经理, 咱哥们也行。

(I'm equally qualified for the very job of the manager)

In (1)a, the addresser uses zan to indicate that he is one member of the community of his friends, and if he is qualified for that job, so are all of his friends, the addresses. In this case, the addresser puts himself in a whole community, which means the addresser gives the addressees an ambiguous sense of $I$ in self-reference and zan in this case is a dependent $I$ instead of an independent or a distinctive one, thus bringing the addressees a sense of intimacy and affinity. Zan practically refers to the addresser himself, but the pragmatic stance of the addresser, which means the 
addresser's perspective of utterance (Ran Yongping, 2007), falls into a certain community which is far from clear-cut in self-reference. This sense of community shortens the psychological distance between the communicators, thereby reaching pragmatic empathy.

In addition to zan, Chinese wo (I, me, myself, etc.) sometimes also puts the addresser himself in an empathetic stance as one member of a whole community. Look at the following examples.

(2) a: 还我河山! 还 我青岛！

(Return our homeland, and return our Qingdao!)

$\mathrm{b}$ : 形势有利于我, 而不利于敌。

(The situation is now in our favor, rather than in the enemies'.)

The Chinese wo mentioned above conveys an ambiguous meaning for it not merely refers to the addresser himself but also extends to the group or the whole community including the addresser. And this kind of ambiguity proves to be a universal pattern in various Chinese person deixis. In view of the connotation of community mentioned in the above example, the deictic centre shifts from the addresser himself to the whole group of people, so as to achieve empathy and to show affinity and social relationship.

In addition, in Chinese there are some self-depreciatory forms of first-person singular deixis used to convey the feeling of modesty, politeness or proximity.

Inspired by Leech's Politeness Principle, Gu(1990) has proposed four maxims under the politeness principle, namely the Self-denigration Maxim, the Address Maxim, the Tact Maxim and the Generosity Maxim, the first two of which are connected closely with the uses of person deixis. According to $\mathrm{Gu}$, the Self-denigration maxim consists of two clauses or sub-maxims: (a) denigrate self and (b) elevate other. In light of this, when we come to the first-person singular deixis in Chinese, the two sub-maxims are given to their full play. Look at the following examples.

(3) a: 我怎么能跟你比。

(How can I compare with you?)

b: 咱怎么能跟你比。

(How can I compare with you?)

c: 等你飞黄腾达了, 可别忘了小弟呀!

(When you are rolling in money someday, please don't forget me.)

By comparison, we can find that both (3) a and (3) b convey the meaning that 'How can I compare with you?' in order to show the addresser's modesty and respect. But the use of zan in (3) b shows much higher pragmatic empathy of the addresser. Since zan has a depreciatory implication, both the respect degree and modesty degree of 咱zan are higher than those of wo. In zan, the addresser, on the pragmatic stance of the addressee, not only denigrates himself, but simultaneously elevates the addressee, thus giving the addressee a sense of friendliness. According to Verschueren's linguistic Adaptation Theory, empathy itself is the result of linguistic choice-making (Verschueren, 2000). Due to the features of "variability", "negotiability" and "adaptability", a language user can make appropriate choices.. Correspondingly, the Chinese often intentionally choose zan (I, me) as a substitute for wo (I, me) to improve the relationship between the addresser and addressee. But in English, there is no such substitute for the first-person singular deixis $I$ or $m e$, and if we want to fully express the Chinese meaning of zan $(I, m e)$ in English, we have to add some other words as a supplement in C-E translation.

In (3)c，小弟xiaodi (your small younger brother) is one of the thousands of self-depreciatory Chinese first-person deixis such as 晚生 wansheng (later born), 在下 zaixia (your subordinate), 小人 xiaoren (small person). The existence of this phenomenon is inextricably connected with Chinese culture in that it is one extended usage of kinship terms conforming to politeness principles. In (3)c, the addresser puts himself into the addressee's shoes, and from the addressee's perspective considers himself inferior to the addressee by adding “小 xiao (small)” to “弟 di (younger brother)" which is often used not among family members, but friends. The choice of xiaodi in place of 我wo(I, me) indicates the addresser's positive appreciation or admiration concerning the addressee's economic influence, social status, and so on. Furthermore, from a deeper perspective, we can see that, by the use of xiaodi for self-reference, the addresser intentionally conforms to the long-held Chinese ideology of power hierarchy, but more importantly he cleverly place himself in a lower hierarchy than the addressee's, thus rendering the addressee a sense of modesty and politeness.

\section{B. I in English}

Unlike the various deictic forms of referring to the addresser himself in Chinese, the first-person singular deixis in English is strictly limited to only one deictic form of expression " $I$ " and its corresponding grammarian variants such as me, my, myself. The deixis "I", which will be more frequently used in both formal and informal linguistic styles in English, intends to emphasize the addresser's existence as an individual. Moreover, contrary to the ambiguous reference of zan and wo in Chinese, its reference is much more clear-cut and specified.

Firstly, " $I$ " is used as a specific reference to only the addresser himself and to emphasize that the opinion expressed is his own opinion. For example,

(4) a. I do not believe Mrs. Long will do any such thing. 
b. I am glad to find that you do not depend on her serving you.

In (4) a, $I$ expresses the addresser's own attitude that according to her knowledge about Mrs. Long, he does not think that Mrs. Long will do such a thing. In order to highlight his own opinion which may differ from most of the addressees, the addresser excludes himself from the community of the addressees by using "I" to indicate himself as an independent individual, thereby giving the addressees a sense of psychological distance or a sense of de-empathy. The same is true of (4) b, the addresser is satisfied with the addressee's deed, so he uses $I$ to show addresser's own opinion other than anyone else's. Furthermore, when expressing his own attitude, the addresser does not trouble to put himself into one community to show a low profile or modesty, but bluntly magnify his own identity with a view to deliberately enlarging the distance from others.

Secondly, "I" makes the person in great power e.g. President, seem much more personal and authoritative. For example,

(5) Tonight, I'm here for a different reason. I've come to a difficult personal decision as to whether or, not $I$ should seek reflection. (Ronald. Reagan, 29 January, 1984)

In announcing his decision to run for a second term as President, Reagan uses $I$ with great frequency. Alongside with the whisper of power is the mention of himself as $I$, which makes the President seem personal, competent, and charismatic. With the frequent use of $I$, Reagan stands on his own stance and de-empathizes so as to give prominence to his campaign slogan of individualism, human rights and freedom which have been hold long by most American citizens as indispensable parts of the American idea of democracy.

\section{Cultural Differences in Chinese zan, wo, Depreciatory Terms and English I}

According to the previous analysis, we can find one stark difference between Chinese first-person singular deixis and its English counterpart is that Chinese often use such deictic terms as zan, wo, xiaodi for empathizing with others, while in English-speaking countries, people are inclined to use $I$ for de-empathizing, with a view to stressing the personal self. With respect to their empathizing and de-empathizing usage, these Chinese first-person singular deixis are defined as pragmatic empathetic deixis which refers to the use of deictic forms to indicate emotional or other psychological distance or proximity between addresser and addressee (Lyons,1977), whereas the English I in those cases is naturally pragmatic de-empathetic deixis..

As regards the de-empathetic deixis $I$, since people brought up in English-speaking countries are influenced by the act code "Do-It-Yourself", the addressers are accustomed to taking the responsibility for their opinions by emphasizing their independence and to thinking things on their own stance, and they will feel more comfortable when excluding themselves from others or any community. Moreover, due to the notion of individualism guided by their long-held human-oriented ideology, they are encouraged to freely air their own thoughts. As a result, the boundary between oneself and others is strengthened.

Compared with English, the Chinese shows a tendency towards putting themselves in a whole community. As we have discussed above, Chinese can use wo and zan to implicitly indicate a certain community instead of only a detached or completely independent individual. Nevertheless, this practice is indissolubly connected with Chinese culture. In traditional Chinese society, the "self" is never regarded as an independent person, but an entity that is subordinated to a certain community of society which is usually based on "family and blood". In Chinese culture, people emphasize a lot on collectivism, so the addresser attaches much significance to maintain a friendly interpersonal relationship by means of pragmatic empathy. And that's why in most cases Chinese are inclined to use such kind of sentences as "we think", "we hold the opinion that" to deliver the addresser's own viewpoint.

On top of that, in the previous analysis, we find that it is obvious that the Chinese zan and wo are general and ambiguous in reference, but the English $I$ tends to be clear-cut and specified to merely refer to the addresser himself. This disparity tells the very difference in the mode of thinking between the Chinese and people in English-speaking countries. In terms of the mode of thinking, it is the intuitive integrity that features in the mindset of traditional Chinese culture, while the analytical logic epitomizes that of the western culture. ( Jia Yuxin, 1997) Just given that the Chinese are keen on integrity and largely depend on imagination and intuition, the Chinese mindset usually manifests an evident sense of generality and ambiguity. On the contrary, since the mindset in western cultures usually abides by an analytical logic, the reference in their utterances must be clear and specific so that it can make sense when analyzed by strict logic in syntax as well as in meaning.

In addition, the exchange of pronouns can shape or confirm the power dynamics and solidarity of a relationship, and the use of Chinese self-depreciatory terms just shows another cultural difference between the Chinese ideology of power hierarchy and of 礼 $\mathrm{Li}$ (politeness) and the western ideology of equality, which to a great extent overlaps with Brown and Gilman's theory of power and solidarity (1960) in this paper.

As to power, it implies social distance and an unequal power relationship between the communicators and that one person is more powerful than another person to the degree that he can influence the other person's behavior. (Jia Yuxin, 1997) Tempered through such a finely-stratified society in its long history when each individual had an asymmetrical relationship with every other individual, Chinese culture has defined politeness, which in Chinese is called $L i$ (礼), as a sanctioned belief that an individual's social behavior ought to live up to the expectations of respectfulness, modesty, attitudinal warmth and refinement according to the individual's own social status in the power hierarchy $(\mathrm{Gu}$, Yueguo, 
1990). However, since the unequal relationship in power hierarchy is apt to arouse psychological distance and show impoliteness, Chinese prefer to use pragmatic empathetic deixis to shorten it by standing in the addressee's shoes to denigrate themselves by placing themselves in lower hierarchy.

With respect to solidarity, on the contrary, it implies an equally sharing experience between people, a degree of closeness and intimacy. In English speaking countries, people are endowed with a strong sense of solidarity or equality, which can be traced back to the period of Renaissance and their mainstream religion of Christianity. Hence, they hold that all are born equal and each is uniquely created as a distinctive and independent individual, and it is undesirable and unreasonable to denigrate self merely for the sake of others' comfortable feelings in social communication. Thus, in communication, their relationship is equal and close in the most natural state of affairs such as religion, occupation, age. In this circumstance, the de-empathetic uses of $I$ not only imply relative equality but keep a comparatively close relationship in communication.

\section{Contrastive Study on ENGLish AND Chinese FIRST-PERson PluRAL DeIXIS}

\section{A. 我们wo-men in Chinese}

Firstly, it is a common practice in Chinese history that wo-men is used empathetically as an implication of the humbleness on the part of the speaker, so as to promote the social relationship, for instance,

(4) 刘姥姥一面走一面笑着说: “你老是‘贵人多忘事了了, 哪里还记得我们?”

(Grannie Liu followed her cackling, "you know what they say: 'Important people have short memories.' 1 wouldn't expect you to remember the likes of us. "(Translated by Hawkes, 1973)

By using the humble wo-men, the speaker stands on the addressee's shoes and takes the initiative to acknowledge his inferiority to the addressee in some aspect, which accordingly gives the addressee a sense of politeness and comfort to promote their relationship.

Secondly, when using wo-men, most Chinese are much dedicated to face work to promote close relationship by empathetically taking the addressees' affective and psychological demands into serious consideration. For example,

(5) a 我们是主张自力更生的。我们希望有外援, 但是我们不能依赖它, 我们依靠自己的努力, 依靠全体军民 的创造力。(Mao Zedong, 1945)

(We stand for self-reliance. We hope for foreign aid but cannot be dependent on it; we depend on our own efforts, on the creative power of the whole army and the entire people.)

$\mathrm{b}$ 在这篇论文中, 我们将介绍一种新的教学方法。

(In this thesis, I attempt to introduce a brand-new teaching method.)

In (5)a, the empathetic use of wo-men intends to keep the addressees' positive face in that by using wo-men, the Chinese leader gets himself emotionally involved with the multitude, so that people will feel an intimate relationship with the Party and the great leader. In (5)b, although he is the only author of the thesis, the Chinese writer stands on the addressees' shoes and uses wo-men to put himself in an equal position with the addressee and to avoid a misunderstanding of his being arrogant. Moreover, by empathetically using wo-men in self-reference, the speaker keeps the addressees' negative face in the avoidance of such feelings of imposition of his own opinions on the addressees, thereby achieving affective convergence with them.

\section{B. We in English}

Firstly, We in English sometimes are used de-empathetically by royal members to underline their sovereign authority and uncommon identity, which is called 'royal we'. For example,

(6) Margaret Thatcher: "We are a grandmother".

This announcement invited a lot of criticism from both her political enemies and the general public simply owing to the de-empathetic use of we rendering her arrogant and inaccessible in affection. Since the "royal we" indicates a sense of social hierarchy, while de-empathetically using it for self-reference by placing herself in a higher hierarchy in comparison with the addressees, the addresser deliberately ignores the addressee's feelings to show her royal authority or other special motives. Moreover, given that the royal we is normally limited to royal members, once it sometimes appears in the speech of non-royals, pretentious grandeur arises in the tone of the speaker.

Secondly, we in English is often used de-empathetically to shun potential responsibilities. In such cases, the relationship among the referents of we is much more serious and business-like and bears less relation to affection. For example,

(7) Today I announce a tax cut for hundreds of thousands of working families on low income. We do this to encourage enterprise; to reward work; to support families to advance ambition not just the few but of the many. (Gordon Brown, 1998)

In (7), we is one "we-exclusive-of-addressee" which means the addressees are not included in the referents of we. Therefore, the speaker organizes messages from his own point of view, and meanwhile, by using we, he cleverly withdraws from the sole spotlight of the public concern in shouldering potential responsibilities. Moreover, as regards the relationship among the speaker and the other referents in we, it is more an instrument rationally catering to the speaker's personal ends than an affective need for spiritual or psychological convergence or satisfaction. 


\section{Cultural Differences in English and Chinese First-person Plural Deixis}

In contrast, we can see the first noticeable difference in English and Chinese first-person plural deixis consists in the different origins of the Chinese humble women and the English royal we. The origin of humble wo-men can date back to the finely-stratified society in ancient China in which each individual had an asymmetrical relationship with every other individual, and common people were too insignificant to call themselves as wo(I). With respect to the royal we in English, it has a quite different cultural origin. In Latin, there used to be only one singular deixis in self-reference, and later the plural form coined for self-reference was only used by the kings. During the 4th century, there were two kings on the throne, the king of the Eastern Rome and the king of the Western Rome. Afterwards, when the two countries were united politically, there still remained two kings. Therefore, a plural first-person deixis VOS was coined for the two kings in self-reference. Then with the development and transformation of the society in history, the authoritative nature of we gradually takes shape in western cultures. Hence, the royals or those with a higher social status prefer we to $I$ which is considered as a mark of ordinary people.

In addition, another cultural difference reflected in women and we is the difference between affective type of relationship in Chinese culture and the instrumental type of relationship in western culture. As discussed in examples (5), the Chinese wo-men attach much importance to face work, which in fact is another way of saying the consideration of communicators' feelings. Therefore, the Chinese people's ceaseless efforts for face work just reflects the affective type of relationship in China, in which "favor" and "face" are two highly-valued factors.(Jia Yuxin,1997) as for the relationship in English speaking countries, as stated in example (7), it is more businesslike and rational and bears less relation to affection or common feelings.

\section{CONCLUSION}

Through the previous analysis, we find that the cultural differences between China and English-speaking countries do result in some pragmatic disparities in verbal communication. In the contrastive study on Chinese and English first-person deixis, we discern the following the cultural differences: a) the difference between the collectivism orientation in Chinese culture (I-less and other-oriented culture) and the individualism orientation in western culture (self-oriented culture); b) the difference between Chinese mindset of intuitive integrity and the mindset of analytical logic in western cultures; c) the difference between the impact of Chinese ideology of power hierarchy and $\mathrm{l}_{L} \mathrm{Li}$ (politeness) and the influence of western ideology of solidarity (or equality); d) the different origins of the royal we in English and the humble wo-men in Chinese; e) and the difference between affective type of relationship in Chinese culture and the instrumental type of relationship in western culture. Keeping those differences in mind will be a help to bridge the gap between the different cultures in our daily intercultural communications. Meanwhile, more detailed study in this orientation still remains to be conducted for our future language teaching and research.

\section{REFERENCES}

[1] Brown, H. D. (1987). Principle of Language Learning and Teaching. New Jersey: Prentice-Hall.

[2] Brown,Roger. \& Gilman,Albert. (1960).The Pronouns of Power and Solidarity, In T.A.Sebeok (Ed.), Style in Language. Cambridge: M.I.T.Press, 253-276.

[3] Bu,Changli. (2003). The Theoretical Explanation and Modern Content of the Structure of Grade. Sociological Research, 1, 21-29.

[4] Gu,Yueguo. (1990).Politeness Phenomena in Modern Chinese. Journal of Pragmatics, 2, 237-257.

[5] He,Ziran. (1991). Pragmatic Empathy in Verbal Communication. Foreign Language Teaching and Research, 4, 11-15.

[6] Jia, Yuxin. (1997). Intercultural Communication. Shanghai: Shanghai Foreign Language Education Press.

[7] Levinson, S. C. (1983). Pragmatics. Cambridge: Cambridge University Press.

[8] Lyons, J. (1977). Semantics (Volume I).Cambridge: Cambridge University Press.

[9] Ran,Yongping. (2007).The Pragmatic Stance of Person Deixis, its Empathic and De-empathic Functions in Interpersonal Discourse. Foreign Language Teaching and Research, 5, 331-337.

[10] Verschueren, J. (2000). Understanding Pragmatics. Beijing: Foreign Language Teaching and Research Press.

Shirong Zhang was born in Lanzhou, China In 1972. She has published more than 20 papers in various journals. She is currently associate professor and a master supervisor in the School of Foreign Languages, Lanzhou University of Technology.

Xiuxiu Wu was born in Yantai, China in 1989. She received her degree of Bachelor of Arts in Foreign Language and Literature from Lanzhou University of Technology, China in June, 2012.

She is currently a postgraduate student in Shannxi Normal University, Xian, China. Her research interests include applied linguistics and pragmatics. During her undergraduate study, one of her theses has already been published in the Chinese core journal, writer magazine.

Yue Feng was born in Hebei, China in 1990. She is currently a postgraduate student in the School of Foreign Languages, Lanzhou University of Technology. 